\title{
AVALIAÇÃO DA CV. MERLOT PARA ELABORAÇÃo DE VINHO TINTO'
}

\author{
Luiz Antenor RIZZON ${ }^{2, *}$, Alberto MIELE ${ }^{3}$
}

\section{RESUMO}

A uva Merlot é uma das responsáveis pelas características dos vinhos tintos de Saint Émillion, região de Bordeaux, França. Foi introduzida no Rio Grande do Sul através da Estação Agronômica de Porto Alegre. É, atualmente, uma das cultivares tinta de Vitis vinifera L. com maior volume de produção da Serra Gaúcha. É utilizada para a elaboração de vinho tinto para ser consumido jovem. O objetivo do presente trabalho foi avaliar o potencial enológico da cv. Merlot para a elaboração de vinho tinto fino. Para isso, realizaramse estudos para caracterizar o cacho, o mosto e o vinho nas safras de 1987 a 1994, em Bento Gonçalves, RS. Os resultados evidenciaram que a cv. Merlot tem cacho com peso médio de 161,9g e baga esférica e pequena, pesando 1,61g. No mosto, o valor médio de açúcar é de $18,4^{\circ}$ Brix; o da acidez total, de $104 \mathrm{meqL}^{-1}$; e o do $\mathrm{pH}$, de 3,21 . O vinho se caracteriza por ter teores médios de $10,8 \% \mathrm{v} / \mathrm{v}$ de álcool; $70,3 \mathrm{meqL}^{-1}$ de acidez titulável; e pH de 3,49. Sob o aspecto sensorial, o vinho Merlot apresenta cor vermelho-violáceo com boa intensidade. Gustativamente distingue-se pela maciez, equilíbrio e fineza.

Palavras-chave: enologia; uva; Vitis vinifera; vinho; caracterização.

\section{SUMMARY}

EVALUATION OF CV. MERLOT TO MAKE RED WINE - Merlot is a traditional grape of the Saint Émillion wines, Bordeaux region - France. It was introduced into, the State of Rio Grande do Sul by the Estação Agronômica de Porto Alegre, Brazil. Today, of the red grape cultivars it shows the largest production in the Serra Gaúcha region. The purpose of this work was to evaluate the enological potential of Merlot grapes for red winemaking. To achieve this purpose, variables related to berry clusters, must and wine were measured between 1987 and 1994 vintages, from Merlot vineyards located in the municipality of Bento Gonçalves. The results showed that Merlot grapes have clusters of medium size (161.9g) and small berries (1.61g). The must showed adequate sugar level (18.4 ${ }^{\circ}$ Brix), high titratable acidity $\left(104 \mathrm{mqL}^{-1}\right)$ and medium $\mathrm{pH} 3.21$. The wine Merlot had an alcohol content of $10.8 \% \mathrm{v} / \mathrm{v}$, titratable acidity of $70.3 \mathrm{meqL} \mathrm{L}^{-1}$ and $\mathrm{pH} 3.49$. With regard the sensory evaluation, Merlot wine showed a good red color intensity with violet reflexes. The mouth feel soft and balanced. Keywords: enology; grape; Vitis vinifera; wine; characterization.

\section{1 - INTRODUÇÃO}

A uva Merlot é uma uva das responsáveis pelas características dos vinhos tintos de Saint Émillion, região de Bordeaux, França. No Rio Grande do Sul, ela foi introduzida através da Estação Agronômica de Porto Alegre, de onde foi difundida para a Serra Gaúcha. Foi a partir da década de 1970 que houve maior incremento de seu plantio nessa região. A safra de 1985, com 6.965t, apresentou a maior produção enquanto que a de 1991, com 4.275t, foi a menor. Nos últimos anos ela tem se mantido próxima a 5.000t. Segundo dados da Divisão de Enologia da Secretaria da Agricultura e do Abastecimento do Estado do Rio Grande do Sul, em 2001 foram vinificados 4,96 milhões de quilos dessa uva.

A cv. Merlot, juntamente com outras do grupo das européias, marcou o início da produção de vinhos finos varietais brasileiros. Atualmente, ocupa o segundo lugar em volume de produção entre as cultivares de Vitis vinifera $\mathrm{L}$. tintas.

O vinho Merlot apresenta aspecto muito bom devido, principalmente, à coloração vermelho-violáceo. Quanto ao olfato, não apresenta aroma pronunciado típico

\footnotetext{
1. Recebido para publicação em 10/07/2002. Aceito para publicação em 18/07/2003 (000938).

${ }^{2}$ EMBRAPA Uva e Vinho, rua Livramento, 515 - Cx. P. 130, CEP 95700000 - Bento Gonçalves, RS. E-mail: rizzon@cnpuv.embrapa.br ${ }^{3}$ EMBRAPA Uva e Vinho. E-mail: miele@cnpuv.embrapa.br

* A quem a correspondência deve ser enviada.
}

como ocorre com o Cabernet Sauvignon. Gustativamente, ele impressiona pelo equilíbrio e maciez.

Entre os estudos efetuados no Rio Grande do Sul com essa cultivar, MANDELLI et al. [11] estudaram o efeito da poda verde sobre os compostos fenólicos do vinho; IDE, RIZZON \& DAUDT [10], avaliaram a influência do tempo de maceração durante a vinificação na Serra Gaúcha.

Devido à importância da uva Merlot na Serra Gaúcha e a pouca disponibilidade de informações, realizou-se o presente trabalho para avaliar o seu potencial para elaboração de vinho tinto. Nesse sentido, foram realizados estudos para acompanhar a maturação e a caracterização da uva, do mosto e do vinho.

\section{2 - MATERIAL E MÉTODOS}

O trabalho foi realizado na EMBRAPA Uva e Vinho, localizada em Bento Gonçalves, RS, nas safras de 1987 a 1994. Utilizaram-se quinze plantas previamente marcadas, em um vinhedo da cv. Merlot formado em 1982 e enxertado sobre o porta-enxerto SO4 (Vitis berlandieri $x$ Vitis riparia - Seleção Oppenheim no 4). As videiras foram conduzidas em espaldeira no espaçamento de $1,5 \mathrm{~m}$ entre plantas e $2,5 \mathrm{~m}$ entre filas.

O acompanhamento da maturação da uva, realizado através de 10 a 12 amostragens por ano, foi feito coletando manualmente 300 bagas em cada amostragem. O trabalho iniciou sempre no dia 22/12 de cada ano e foi con- 
cluído por ocasião da colheita da uva. As amostras foram levadas ao laboratório em sacos de plástico, efetuando a pesagem de três grupos de 100 bagas para determinar a evolução do peso da baga. A seguir foram esmagadas manualmente para extrair o mosto, que foi centrifugado. No mosto analisaram-se as variáveis ${ }^{\circ} \mathrm{Brix}$, acidez titulável e pH, através de métodos físico-químicos [1].

As variáveis da uva foram avaliadas através de medidas efetuadas por ocasião da colheita. O peso do cacho, o número de bagas /cacho, o peso da ráquis e a proporção peso da ráquis/peso do cacho foram obtidos através das medidas feitas em 15 cachos de uva colhidos ao acaso. O peso da semente e a relação peso da semente/peso da baga foram determinados retirando as sementes de 100 bagas.

As características da baga como peso, comprimento e largura da mesma e peso da semente foram obtidas através da avaliação efetuada por ocasião da colheita da uva. O peso da baga foi determinado através da pesagem de três grupos de 100 bagas. A medida do comprimento e da largura foram efetuadas com um paquímetro e o resultado final corresponde à média de 30 bagas.

As análises do mosto - densidade, ${ }^{\circ}$ Brix, acidez titulável, pH, ácido tartárico, ácido málico e relação ácido tartárico/ácido málico - foram obtidas do mosto extraído por ocasião do esmagamento da uva para vinificação.

O ácido tartárico e o ácido málico foram analisados através da cromatografia líquida de alta eficiência (CLAE). Utilizou-se um cromatógrafo líquido Varian operando em condição isocrática, um detector espectrofotométrico UV/VIS, modelo UV-50 e um injetor Rheodyne 7125 , com volume de $20 \mu \mathrm{L}$. A separação do ácido tartárico e do ácido málico foi realizada em uma coluna $\mathrm{MCH}-$ NCAP-5 de $15 \mathrm{~cm} \times 4,6 \mathrm{~mm}$ de diâmetro interno. O detector foi fixado em um comprimento de onda de $212 \mathrm{~nm}$. Na eluição utilizou-se um solvente constituído de água ultrapura acidificada com ácido fosfórico a pH 2,5 [2].

Os vinhos foram elaborados em pequena escala, sendo realizadas três microvinificações de $18 \mathrm{~kg}$ de uva em cada safra. Inicialmente, a baga foi separada da ráquis e, a seguir esmagada com uma desengaçadeiraesmagadeira, momento em que retiraram-se amostras de mosto para análise. O mosto foi, então, colocado em recipiente de $20 \mathrm{~L}$, adaptado com válvula de Müller, adicionado de $\mathrm{SO}_{2}$ na quantidade de $50 \mathrm{mgL}^{-1}$ e de leveduras secas ativas (Saccharomyces cerevisiae), na proporção de $0,20 \mathrm{gL}^{-1}$. O tempo de maceração foi de cinco dias, com duas remontagens diárias. A fermentação alcoólica ocorreu em uma sala com temperatura entre $23^{\circ} \mathrm{C} \mathrm{e} 25^{\circ} \mathrm{C}$. $\mathrm{O}$ vinho foi trasfegado, filtrado, engarrafado e depois analisado.

Inicialmente, foi feita a avaliação sensorial individual para descrever as principais características do vinho Merlot. As determinações físico-químicas tais como a densidade, álcool, acidez titulável, acidez volátil, $\mathrm{pH}$, extrato seco, açúcares redutores, extrato seco reduzi- do, cinzas, alcalinidade das cinzas, nitrogênio total e dióxido de enxofre total foram feitas, conforme metodologia descrita por RIBÉREAU-GAYON et al. [17]. As antocianinas foram determinadas pelo método de diferença de $\mathrm{pH}$ e os taninos através da hidrólise ácida [15, 16]. A densidade ótica a 420nm e 520nm e os polifenóis totais foram determinados através de um espectrofotômetro UV/VIS, com cubetas de $1 \mathrm{~mm}$ e $10 \mathrm{~mm}$ de percurso ótico, para os índices de cor e os polifenóis totais, respectivamente.

Os compostos voláteis aldeído acético, acetato de etila, metanol, 1-propanol, 2-metil-1-propanol, 2-metil1-butanol e 3-metil-1-butanol, foram determinados por cromatografia gasosa. Utilizou-se um aparelho equipado com um detector de ionização de chama e coluna de aço inoxidável, Carbowax 600 a 5\%, mais Hallcomid M-18 OL como fase estacionária e Chromosorb $\mathrm{W}$ de 60-80mesh como suporte, de 3,2m de comprimento e de $1 / 8$ " de diâmetro interno. A amostra de vinho $(3 \mu \mathrm{L})$ foi injetada diretamente no aparelho após ter recebido $10 \%$ do volume de uma solução de 4-metil-2-pentanol a $1 \mathrm{gL}^{-1}$ como padrão interno [3]. O teor de $\mathrm{P}$ foi determinado por colorimetria usando o molibdato de amônio. O Ca, Mg, Mn, Fe, Cu e Zn foram analisados por absorção atômica, enquanto que o K, Na, Li e Rb por emissão de chama [14].

\section{3 - RESULTADOS E DISCUSSÃO}

\section{1 - Maturação da uva}

A evolução do peso da baga da uva Merlot a partir de 22/12 até a colheita está indicada na Figura 1.

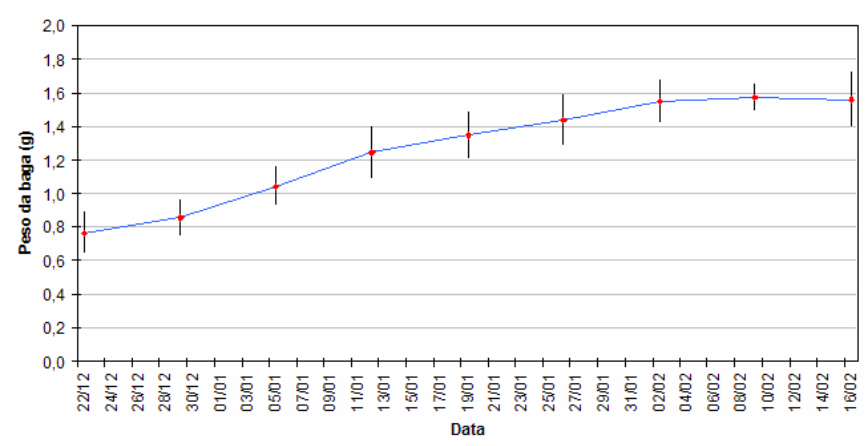

FIGURA 1. Evolução do peso da baga durante a maturação da uva Merlot. Média e desvio padrão das safras de 1987 a 1994.

Constatou-se aumento contínuo do peso da baga até a avaliação efetuada em 02/02. Na semana seguinte observou-se estabilização do peso e, após, uma pequena redução, constatada próxima à colheita e pode ter sido conseqüência da evaporação da água através da película. Observou-se que do início até o final do estudo a baga da cv. Merlot praticamente duplicou de peso. Guanto a seu tamanho ela tem bagas pequenas, 
pois pesam menos que $2,0 \mathrm{~g}[12,13]$. Deve-se considerar que o peso da baga na maturação está relacionado com o acúmulo de açúcar e com os teores de umidade do solo e da atmosfera (5). Em princípio, bagas pequenas favorecem a liberação de maior quantidade de minerais para o mosto, especialmente de $\mathrm{K}$, $\mathrm{Ca}$ e $\mathrm{Mg}$, que interferem na salificação dos ácidos e conseqüentemente no $\mathrm{pH}$ e na acidez titulável do vinho. O peso da baga está relacionado também ao número de sementes.

A evolução do ${ }^{\circ}$ Brix do mosto da cv. Merlot está indicada na Figura 2.

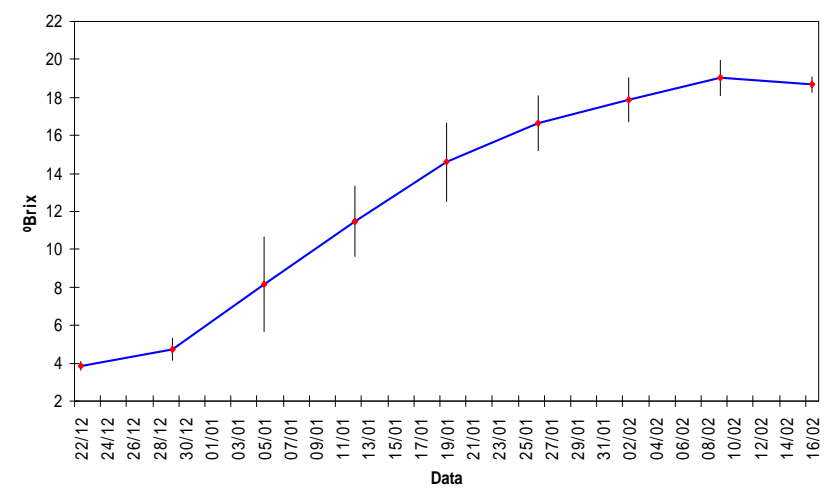

FIGURA 2. Evolução do ${ }^{\circ}$ Brix do mosto durante a maturação da uva Merlot. Média e desvio padrão das safras de 1987 a 1994.

Observou-se pequena variação do ${ }^{\circ}$ Brix do mosto na primeira semana. A partir de 29/12 até uma semana antes da colheita, incrementos semanais mais importantes do ${ }^{\circ}$ Brix foram detectados. Os primeiros sinais da mudança de cor das bagas ocorreram entre 22/12 e 29/12, enquanto que o início da maturação ocorreu no período de 29/12 a 05/01 nas safras precoces e no período de 05/01 a 12/01, nas safras tardias.

A data da colheita da uva Merlot variou de 10/02 a 20/02. A determinação do momento da colheita é definido, principalmente, pelo teor de açúcar do mosto. No entanto, em algumas safras a uva foi colhida antecipadamente devido ao excesso de umidade e ao ataque de Botrytis cinerea, fungo que causa a podridão cinzenta do cacho de uva.

Guanto à acidez titulável (Figura 3), observou-se um aumento até 29/12, o que indica que a baga se encontrava ainda no Estágio I de crescimento. Após esse estágio, constatou-se uma diminuição da acidez titulável ao longo da maturação. Nas últimas duas avaliações efetuadas antes da colheita, a redução da acidez titulável foi menor. Entre os fatores que determinam a redução da acidez titulável do mosto, destacam-se a diluição dos ácidos orgânicos devido ao aumento do volume da baga, a mobilização dos ácidos orgânicos e dos minerais durante a maturação da uva e a combustão respiratória, especialmente no caso do ácido málico [4, 6, 7].

A evolução da acidez titulável do mosto da cv. Merlot foi acompanhada também, pelo pH (Figura 4).

Observou-se, na semana compreendida entre 22/12 e 29/ 12 uma diminuição do valor do $\mathrm{pH}$, que corresponde ao período em que a baga se encontra ainda no Estágio I de crescimento. Após esse estágio, constatouse aumento no valor do $\mathrm{pH}$ até uma semana antes da colheita da uva, quando o valor médio do $\mathrm{pH}$ estabilizou. O aumento mais importante do valor do $\mathrm{pH}$ foi observado no período de 05/01 até 26/01, que corresponde à redução mais intensa da acidez titulável do mosto. Os fatores determinantes do aumento do $\mathrm{pH}$ do mosto são os mesmos que interferem na acidez titulável [4, 6, 7]. A cv. Merlot se caracterizou por apresentar mostos com pH baixos, sempre inferiores a 3,30, o que interfere nas características do vinho.

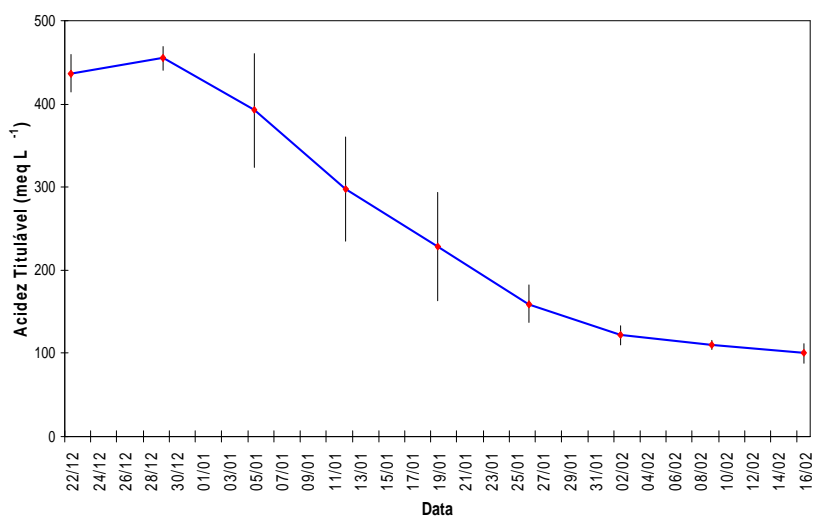

FIGURA 3. Evolução da acidez titulável do mosto durante a maturação da uva Merlot. Média e desvio padrão das safras de 1987 a 1994.

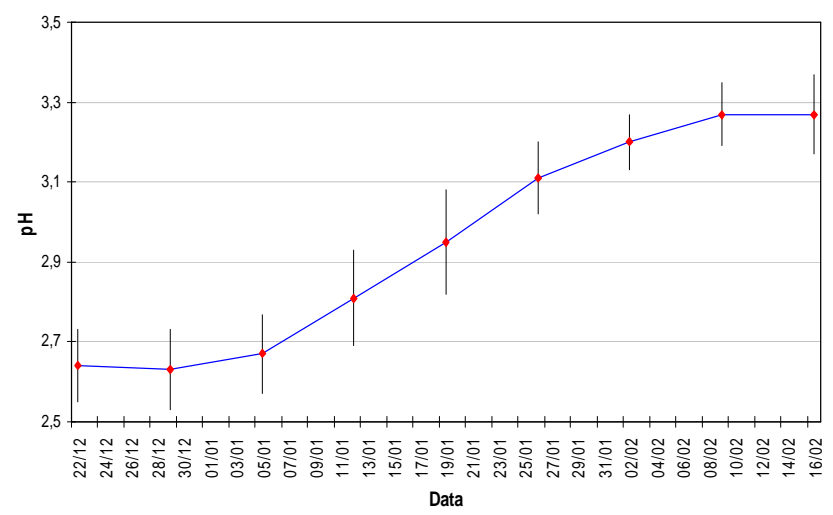

FIGURA 4. Evolução do $\mathrm{pH}$ do mosto durante a maturação da uva Merlot. Média e desvio padrão das safras de 1987 a 1994.

\section{2 - Características da uva}

As características físicas da uva Merlot são indicadas na Tabela 1.

A cv. Merlot apresenta cacho de tamanho médio, de formato cilíndrico, alado, solto, com pedúnculo fino, longo e lenhoso na inserção $[8,12,13]$. O peso médio do cacho variou de 114,2g na safra de 1987 a 212,2g em 1990. $\mathrm{O}$ número médio de bagas/cacho, em todas as safras estudadas, foi de 122,0 bagas. O número de bagas/ca- 
cho é definido através do pegamento do fruto [9]. Em alguns casos, ataques de míldio podem reduzir o número de bagas/cacho [6, 7]. O peso do cacho depende diretamente do número e do tamanho das bagas.

TABELA 1. Características físicas do cacho e da baga da uva Merlot. Média e desvio padrão das safras de 1987 a 1994.

\begin{tabular}{|c|c|c|c|c|c|c|c|c|c|c|}
\hline \multirow{2}{*}{ Variável } & \multicolumn{8}{|c|}{ Safra } & \multirow{2}{*}{ Média } & \multirow{2}{*}{$\begin{array}{l}\text { Desvio } \\
\text { padrăo }\end{array}$} \\
\hline & $\overline{1987}$ & 1988 & 1989 & 1990 & 1991 & 1992 & 1993 & $\overline{1994}^{n}$ & & \\
\hline \multicolumn{11}{|l|}{ Caracteristicas do cacho } \\
\hline Peso do cacho (g) & 114,2 & 120,8 & 139,0 & 212,2 & 143,1 & 184,9 & 185,4 & 4195,4 & $+161,9 \pm$ & $\pm 37,0$ \\
\hline Número de bagas/cacho & 70,2 & 77,0 & 97,9 & 142,3 & 95,8 & 3157,1 & 158,6 & 177,2 & $122,0 \pm$ & $\pm 41,4$ \\
\hline Peso da ráquis (g) & 4,2 & 5,1 & 5,4 & 6,8 & 5,1 & 7,0 & 5,5 & 4,6 & & $\pm 1,0$ \\
\hline Peso da ráquis/Peso do cacho (\%) & 3,7 & 4,2 & 3,9 & 3,2 & 3,5 & 3,8 & 3,0 & 2,4 & & $\pm 0,6$ \\
\hline \multicolumn{11}{|l|}{ Caracteristicas da baga } \\
\hline Peso da baga $(g)$ & 1,69 & 1,69 & 1,56 & 1,56 & 1,62 & 1,57 & 1,59 & 91,77 & $1,61 \pm$ & $\pm 0,12$ \\
\hline Comprimento da baga $(\mathrm{cm})$ & 1,36 & 1,28 & 1,26 & 1,26 & 1,38 & 1,28 & 1,31 & $1 \quad 1,40$ & $1,31 \pm$ & $\pm 0,07$ \\
\hline Largura da baga (cm) & 1,36 & 1,30 & 1,28 & 1,28 & 1,37 & 1,29 & 1,32 & $2 \quad 1,44$ & $1,32 \pm$ & $\pm 0,07$ \\
\hline Comprimento/Largura da baga & 1,00 & 0,98 & 0,98 & 0,98 & 1,01 & 0,99 & 0,99 & 90,97 & $0,99 \pm$ & $\pm 0,01$ \\
\hline Peso da semente (mg) & 41,3 & 44,1 & 39,2 & 39,2 & 41,6 & 36,1 & 35,2 & 249,5 & & $\pm 4,7$ \\
\hline Peso das sementes/Peso da baga (\%) & 3,6 & 4,4 & 3,3 & 3,3 & 3,7 & 3,0 & 3,0 & 3,3 & & $\pm 0,5$ \\
\hline
\end{tabular}

A uva Merlot apresenta ráquis com peso médio de $5,5 \mathrm{~g}$, e participa com 3,5\% do peso do cacho. As bagas são pequenas, pois medem em média $1,31 \mathrm{~cm}$ de comprimento por $1,32 \mathrm{~cm}$ de largura. São de formato ligeiramente oval e não se desprendem facilmente do cacho. $\mathrm{O}$ tamanho e o peso da baga estão relacionados, também, com a disponibilidade e absorção de água pela planta no período de maturação da uva. O peso médio da baga da uva Merlot $(1,61 \mathrm{~g})$ a classifica como pequena. Geralmente, a baga possui uma semente, embora é comum encontrar-se bagas com duas ou três sementes. As sementes são periformes e grandes, representando em média $3,5 \%$ do peso da baga, que corresponde ao valor indicado para uvas de vinho [5].

\section{3 - Características do mosto}

As principais características analíticas do mosto da uva Merlot são indicadas na Tabela 2.

TABELA 2. Características analíticas do mosto da uva Merlot. Média e desvio padrão das safras de 1987 a 1994.

\begin{tabular}{|c|c|c|c|c|c|c|c|c|c|c|}
\hline \multirow{2}{*}{ Variável } & \multicolumn{8}{|c|}{ Safra } & \multirow{2}{*}{ Média } & \multirow{2}{*}{$\begin{array}{l}\text { Desvio } \\
\text { padrão }\end{array}$} \\
\hline & $\overline{1987}$ & 1988 & 1989 & 1990 & 1991 & 19921 & 1993 & 1994 & & \\
\hline Densidade a $20^{\circ} \mathrm{C}\left(\mathrm{gmL}^{-1}\right)$ & 1,071 & 1,072 & 1,076 & 51,082 & $-1,088$ & 31,079 & 1,081 & 1,077 & $1,078 \pm$ & $\pm 0,006$ \\
\hline @Brix & 16,1 & 17,0 & 17,9 & $\begin{array}{l}9 \\
19,2\end{array}$ & 20,7 & 18,6 & 19,0 & 18,3 & $18,4 \pm$ & $\pm 1,4$ \\
\hline Acidez titulável (meqL $\left.{ }^{-1}\right)$ & 110 & 106 & 82 & 114 & 86 & 112 & 116 & 108 & $104 \pm$ & $\pm 12,9$ \\
\hline Brix/Acidez titulável & 19,4 & 21,3 & 28,9 & 22,3 & 31,8 & 22,1 & 21,8 & 22,6 & $23,8 \pm$ & $\pm 4,3$ \\
\hline $\mathrm{pH}$ & 3,20 & 3,12 & 3,23 & $3 \quad 3,29$ & 3,30 & 3,17 & 3,32 & 3,20 & $3,21 \pm$ & $\pm 0,07$ \\
\hline Ácido tartárico $\left(\mathrm{gL}^{-1}\right)$ & 2,3 & 5,9 & 8,1 & 5,7 & 4,2 & 5,6 & 4,8 & 5,7 & & $\pm 1,7$ \\
\hline Ácido málico $\left(\mathrm{gL}^{-1}\right)$ & 3,6 & 2,4 & 3,3 & 3,5 & 4,3 & 4,6 & 3,6 & 3,3 & & $\pm 0,7$ \\
\hline Ácido tartárico/Ácido málico & 0,6 & 2,5 & 2,5 & 1,6 & 1,0 & 1,2 & 1,3 & 1,7 & & $\pm 0,7$ \\
\hline
\end{tabular}

Quanto à densidade e ao ${ }^{\circ}$ Brix do mosto, observaram-se variações importantes nas diferentes safras vitícolas. Os valores mais baixos $-1,071$ para a densidade e 16,1 para ${ }^{\circ}{ }^{\circ}$ Brix foram detectados na safra de 1987, e os mais altos, 1,088 para a densidade e 20,7 para o ${ }^{\circ}$ Brix, na safra de 1991 , considerada uma das melhores. Os valores médios da densidade e do ${ }^{\circ} \mathrm{Brix}$ do mosto mostram que a cv. Merlot apresenta bom po- tencial para a formação de açúcar.

Quanto à acidez titulável, detectou-se teor médio de $104 \mathrm{meq} \mathrm{L}^{-1}$ que, juntamente com o valor médio do pH de 3,21 indicam que a cv. Merlot apresenta, na Serra Gaúcha, acidez adequada para a produção de vinho tinto. A relação ${ }^{\circ}$ Brix/Acidez titulável é utilizada como índice de maturação da uva para vinificação. Os valores dessa relação para o mosto dessa cultivar próximos a 30, como foi constatado na safra de 1991, parecem ser os mais adequados. A utilização dessa variável como índice de maturação da uva deve ser feita com precaução, pois o aumento do açúcar nem sempre corresponde à igual redução da acidez titulável [18]. Além disso, ela não é indicada para comparar mostos de diferentes cultivares, pois os parâmetros podem ser muito diferentes.

A relação ácido tartárico/ácido málico evidenciou uma predominância do ácido tartárico sobre o málico, pois o valor médio foi de 1,6. Conseqüentemente, esse valor determina que a acidez do vinho depende mais do ácido tartárico do que do ácido lático formado na fermentação malolática a partir do málico.

\section{4 - Características analíticas do vinho}

As análises básicas do vinho Merlot são indicadas na Tabela 3.

A densidade do vinho é conseqüência da graduação alcoólica e da quantidade de açúcar residual. Observou-se variabilidade acentuada no teor de álcool dos vinhos entre as safras vitícolas. Os maiores valores foram registrados em 1991, devido à maturação especial da uva nesse ano; o teor alcoólico foi inferior a 10\% v/v em 1993.

TABELA 3. Características analíticas do vinho Merlot. Média e desvio padrão das safras de 1987 a 1994.

\begin{tabular}{|c|c|c|c|c|c|c|c|c|c|c|}
\hline \multirow[t]{2}{*}{ Variável } & \multicolumn{8}{|c|}{ Safra } & \multirow[t]{2}{*}{ Média } & \multirow{2}{*}{$\begin{array}{l}\text { Desvio } \\
\text { padrão }\end{array}$} \\
\hline & 1987 & 1988 & 1989 & 1990 & 1991 & 1992 & 1993 & 1994 & & \\
\hline Densidade a $20^{\circ} \mathrm{C}\left(\mathrm{g} \mathrm{mL^{-1 }}\right)$ & 0,9957 & 0,9937 & 0,9951 & 0,9943 & 0,9925 & 50,9944 & 0,9960 & 0,9954 & $0,9946 \pm$ & $6 \pm 0,001$ \\
\hline Álcool (\% V/v) & 11,03 & 10,86 & 10,36 & 11,03 & 12,38 & $\begin{array}{l}310,90 \\
\end{array}$ & 9,81 & 10,00 & $10,80 \pm$ & $0 \pm 0,80$ \\
\hline Acidez titulável (meq $\mathrm{L}^{-1}$ ) & 74 & 60 & 64 & 74 & 64 & 82 & 74 & 70 & & $3 \pm 7,2$ \\
\hline Acidez volátil (meq $\mathrm{L}^{-1}$ ) & 8 & 6 & 5 & 6 & 7 & 7 & 6 & 7 & & $5 \pm 0,9$ \\
\hline $\mathrm{pH}$ & 3,51 & 3,56 & 3,66 & 3,48 & 3,59 & $9 \quad 3,50$ & 3,35 & 3,24 & $3,49 \pm$ & $\pm 0,13$ \\
\hline Extrato seco $\left(g L^{-1}\right)$ & 23,2 & 18,4 & 23,2 & 23,2 & 22,0 & 21,6 & 20,8 & 19,6 & & $5 \pm 1,8$ \\
\hline Açúcares redutores $\left(g \mathrm{~L}^{-1}\right)$ & 2,10 & 2,06 & 3,08 & 32,17 & 2,34 & $\begin{array}{l}4 \quad, 14 \\
4\end{array}$ & 2,37 & 3,23 & & $4 \pm 0,5$ \\
\hline Extrato seco reduzido (g $\left.\mathrm{L}^{-1}\right)$ & 22,10 & 17,34 & 21,12 & 22,03 & 20,66 & $6 \quad 20,46$ & 19,43 & 17,37 & $20,06 \pm$ & $6 \pm 1,9$ \\
\hline Relação álcool em peso/Extrato seco reduzido & 3,99 & 5,01 & 3,92 & 4,01 & 4,79 & 94,26 & 4,04 & 4,60 & & $3 \pm 0,42$ \\
\hline Cinzas $\left(g \mathrm{~L}^{-1}\right)$ & 2,80 & 2,50 & 1,90 & 2,00 & 2,20 & 1,85 & 2,05 & 2,35 & & $\pm 0,3$ \\
\hline Alcalinidade das cinzas (meq $L^{-1}$ ) & 20,8 & 18,4 & 20,0 & 19,6 & 20,8 & 15,2 & 17,6 & 22,0 & & $3 \pm 2,2$ \\
\hline Nitrogênio total (mg L-1) & 134 & 189 & 210 & 215 & 217 & 210 & 149 & 158 & & $5 \pm 33,6$ \\
\hline Polifenóis totais (1 280) & 39,5 & 29,4 & 30,5 & $5 \quad 31,5$ & 34,1 & 27,5 & 26,2 & 31,9 & & $3 \pm 4,1$ \\
\hline Taninos $\left(\mathrm{g} \mathrm{L}^{-1}\right)$ & 2,20 & 0,80 & 1,12 & 1,26 & 1,37 & 1,04 & 1,24 & 1,39 & $1,30 \pm$ & $\pm 0,41$ \\
\hline Antocianinas ( $\mathrm{mg} \mathrm{L} \mathrm{L}^{-1}$ ) & 282 & 199 & 344 & 339 & 295 & 300 & 137 & 289 & & $3 \pm 70,5$ \\
\hline DO $420 \mathrm{~nm}$ & 0,197 & 0,110 & 0,144 & $4 \quad 0,182$ & 0,244 & 0,165 & 0,141 & 0,184 & $0,171 \pm$ & $1 \pm 0,04$ \\
\hline DO $520 \mathrm{~nm}$ & 0,130 & 0,135 & 0,200 & 0,263 & 0,390 & 0,216 & 0,209 & 0,314 & $0,245 \pm$ & $5 \pm 0,08$ \\
\hline Intensidade de cor (DO $420+\mathrm{D} 520)$ & 0,427 & 0,245 & 0,344 & $4 \quad 0,445$ & 0,634 & 0,381 & 0,350 & 0,498 & $0,416 \pm$ & $6 \pm 0,12$ \\
\hline Coloraçăo (DO 420/DO 520) & 0,857 & 0,814 & 0,720 & 0,692 & 0,626 & 0,764 & 0,675 & 0,586 & $0,717 \pm$ & $7 \pm 0,09$ \\
\hline Dióxido de enxơre total ( $\mathrm{mg} \mathrm{L}^{-1}$ ) & 90,9 & 73,0 & 91,0 & 76,8 & 28,8 & 102,4 & 47,4 & 32,0 & $67,8 \pm$ & $3 \pm 28,3$ \\
\hline
\end{tabular}

A acidez titulável do vinho Merlot se enquadra nos limites estabelecidos pela Legislação Brasileira, que é de 55 a 130meq $\mathrm{L}^{-1}$. Os resultados analíticos da acidez titulável confirmam uma redução nos valores do vinho em relação ao mosto. Os valores da acidez volátil são 
baixos, o que confirma o grau de sanidade da uva e as condições favoráveis que transcorreram durante a fermentação alcoólica. Observou-se aumento no valor do pH na transformação do mosto em vinho, provavelmente em decorrência da extração do potássio por ocasião do período de maceração.

Quanto ao extrato seco e ao extrato seco reduzido os valores indicam que a cultivar Merlot apresenta tendência a produzir vinhos com baixo teor, logo com pouco corpo.

O teor de açúcar mostra que houve transformação completa dessa substância do mosto. Todos os vinhos, exceto o de 1989, apresentaram menos de $3,0 \mathrm{~g} \mathrm{~L}^{-1}$ de açúcar residual, classificados, portanto, como vinhos secos.

As cinzas correspondem aos elementos minerais presentes no vinho e representam aproximadamente $10 \%$ do valor do extrato seco reduzido. Para o vinho tinto de mesa, o teor mínimo estabelecido pela Legislação Brasileira é de $1,5 \mathrm{~g} \mathrm{~L}^{-1}$. O vinho Merlot, em todas as safras, apresentou teor de cinzas acima do mínimo estabelecido por essa legislação. A alcalinidade das cinzas indica o grau de salificação dos ácidos do vinho. Teor baixo representa maior proporção de ácidos livres. O vinho se caracterizou por ter valor baixo de alcalinidade das cinzas, conseqüentemente, maior proporção de ácidos orgânicos livres, o que contribuiu para o valor baixo do $\mathrm{pH}$ dos vinhos.

O nitrogênio total está presente no vinho Merlot em baixas concentrações, variáveis em função da safra. Com relação aos polifenóis totais e aos taninos, ele apresentou baixos teores, reflexo da composição da uva. Detectou-se, ainda, teor de antocianinas relativamente baixo, alcançando $344 \mathrm{mg} \mathrm{L}^{-1} \mathrm{em} \mathrm{1989.} \mathrm{A} \mathrm{pre-}$ dominância da DO 520nm determina uma coloração vermelho-vivo típica para o vinho Merlot.

O teor de dióxido de enxofre total corresponde àquele adicionado por ocasião do esmagamento da uva e do engarrafamento do vinho.

Os principais elementos minerais do vinho Merlot são indicados na Tabela 4.

TABELA 4. Elementos minerais do vinho Merlot. Média e desvio padrão das safras de 1988 a 1994.

\begin{tabular}{llllllllc}
\hline Minerais $\left(\mathrm{mg} \mathrm{L}^{-1}\right)$ & \multicolumn{7}{c}{ Safra } & \multirow{2}{*}{ Média $\begin{array}{l}\text { Desvio } \\
\text { padrão }\end{array}$} \\
\cline { 2 - 8 } & 1988 & 1989 & 1990 & 1991 & 1992 & 1993 & 1994 & \\
$\mathrm{~K}$ & 941 & 1100 & 971 & 965 & 909 & 839 & 1009 & $962 \pm 81$ \\
$\mathrm{Ca}$ & 48 & 69 & 61 & 49 & 70 & 73 & 64 & $62 \pm 10$ \\
$\mathrm{Mg}$ & 64 & 69 & 70 & 71 & 73 & 65 & 68 & $69 \pm 3$ \\
$\mathrm{Na}$ & 1,9 & 7,2 & 2,7 & 5,2 & 2,8 & 1,8 & 2,8 & $3,5 \pm 2,0$ \\
$\mathrm{Mn}$ & 1,0 & 1,4 & 1,1 & 1,3 & 1,2 & 1,4 & 1,5 & $1,3 \pm 0,2$ \\
$\mathrm{Fe}$ & 2,4 & 2,3 & 1,8 & 1,7 & 1,4 & 1,5 & 1,4 & $1,6 \pm 0,6$ \\
$\mathrm{Cu}$ & 2,2 & 0,9 & 0,7 & 0,7 & 0,8 & 0,1 & 0,1 & $0,8 \pm 0,7$ \\
$\mathrm{Zn}$ & 1,1 & 0,4 & 0,5 & 0,5 & 0,9 & 0,4 & 0,4 & $0,6 \pm 0,3$ \\
$\mathrm{Li}$ & 1,0 & 4,6 & 2,5 & 1,2 & 1,0 & 1,7 & 0,1 & $1,7 \pm 1,5$ \\
$\mathrm{Rb}$ & 5,8 & 6,1 & 6,0 & 4,7 & 6,1 & 5,4 & 5,4 & $5,6 \pm 0,5$ \\
$\mathrm{P}$ & 71 & 53 & 37 & 84 & 53 & 50 & 70 & $60 \pm 16$ \\
\hline${ }^{*} \mu \mathrm{L}^{-1}$. & & & & & & & &
\end{tabular}

A composição mineral do vinho se origina, essencialmente, da parte sólida da uva, embora as operações tecnológicas de vinificação, estabilização, conservação e envelhecimento causam modificações acentuadas.

O K é o cátion mais importante, pois os teores detectados no vinho Merlot, embora baixos em relação a outros vinhos tintos, representa aproximadamente $40 \%$ das cinzas. O K, além de participar da salificação dos ácidos orgânicos, interfere na formação do bitartarato de potássio. O Ca é outro cátion presente em concentrações relativamente elevadas. A determinação do teor de Ca é necessária para monitorar possiveis precipitações de bitartarato de cálcio, que ocorrem lentamente e geralmente no produto já engarrafado. Um dos fatores que podem aumentar o teor de $\mathrm{Ca}$ no vinho é a pulverização de calda bordalesa nos vinhedos para o controle de doenças fúngicas. A variação observada no teor de Ca do vinho Merlot, entre diferentes safras, além da aplicação da calda bordalesa, pode ser conseqüência da prensagem do mosto por ocasião da descuba.

O teor de $\mathrm{Mg}$ geralmente é superior ao de $\mathrm{Ca}$, pois os seus sais são mais solúveis. O teor de $\mathrm{Mg}$ detectado no vinho Merlot é considerado baixo e reflete acumulação desse elemento no solo. Os demais elementos minerais analisados, exceto o $\mathrm{P}$, aparecem em pequenas quantidades. No caso do $\mathrm{Fe}$ e do $\mathrm{Cu}$ eles representam acentuada importância enológica, uma vez que participam das reações de oxirredução, podendo ser responsáveis por turvações. Em relação ao Fe, em todas as safras constataram-se teores baixos que não interferem na estabilidade do vinho. No caso do $\mathrm{Cu}$, observou-se teor elevado no vinho em 1988, provavelmente devido ao tratamento com calda bordalesa na uva próximo à colheita.

A determinação do $\mathrm{Li}$ e do $\mathrm{Rb}$ é importante para diferenciar os vinhos de diferentes regiões vitícolas. O vinho Merlot sempre apresentou teor baixo desses dois cátions. A variação observada no teor de fósforo em função das safras, pode ser atribuída ao grau de prensagem da uva por ocasião da vinificação.

Com relação aos compostos voláteis (Tabela 5), o vinho Merlot se caracterizou por apresentar teor baixo de etanal, possivelmente em decorrência da utilização de doses reduzidas de $\mathrm{SO}_{2}$ antes da fermentação alcoólica.

O teor de acetato de etila detectado sempre foi inferior ao limiar de percepção, que é de cerca de $180 \mathrm{mgL}^{-1}$ para o vinho. O teor reduzido de acetato de etila é devido ao bom estado sanitário da uva e das condições favoráveis da fermentação alcoólica.

TABELA 5. Compostos voláteis do vinho Merlot. Média e desvio padrão das safras de 1988 a 1994.

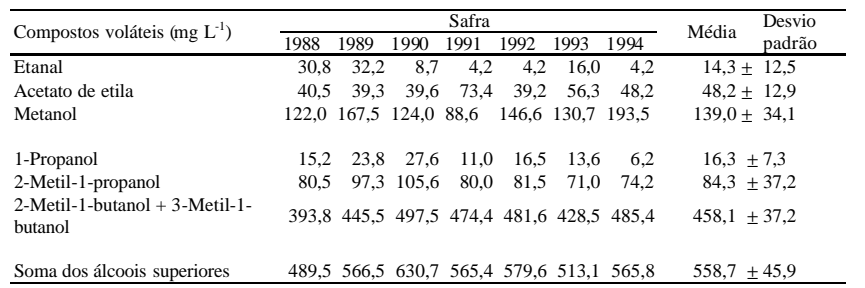

O teor médio de metanol corresponde àquele indicado para vinho titno de Vitis vinifera L. [19, 20]. A Le- 
gislação Brasileira estabelece em $350 \mathrm{mg} \mathrm{L}^{-1}$ o teor máximo de metanol nos vinhos.

Quanto ao teor de álcoois superiores, o vinho Merlot se caracteriza por apresentar teor elevado de 2-metil-1butanol e 3-metil-1-butanol (álcoois amílicos), semelhantes aos valores encontrados no vinho Cabernet Sauvignon e Cabernet Franc [20].

\section{5 - Características sensoriais do vinho}

O vinho Merlot tem cor vermelho-violáceo que lhe confere aspecto visual distinto. A intensidade de cor é variável com as safras. Assim, em 1991, ele apresentou maior intensidade de cor e ao contrário, em 1988, menor intensidade.

No nariz não apresenta característica marcante e aroma pronunciado como no caso do Cabernet Sauvignon. O vinho Merlot geralmente apresenta nota floral e frutada.

Na boca, se distingue pela maciez, equilíbrio e fineza sem ser muito encorpado. Trata-se de um vinho que se destaca mais pelo gosto e aspecto do que pelo aroma.

\section{4 - CONCLUSÕES}

A cv. Merlot se caracteriza por ter cacho de tamanho médio e de peso médio $(161,9 \mathrm{~g})$ e bagas pequenas $(1,61 \mathrm{~g})$. O mosto apresenta teor elevado de açúcar, média de $18,4^{\circ}$ Brix, e equilíbrio entre os teores de açúcar e de acidez.

Na vinificação, observa-se redução da acidez titulável e aumento do $\mathrm{pH}$ do vinho em relação ao mosto.

O vinho se distingue por ter cor vermelho-violáceo, maciez, equilíbrio e fineza, e aroma floral e frutado pouco intenso.

Trata-se de uma cultivar cujo plantio deve ser incentivado na Serra Gaúcha, tanto para a produção de vinho varietal como para cortes com outros vinhos tintos finos.

\section{5 - REFERÊNCIAS BIBLIOGRÁFICAS}

[1] AMERINE, M.A.; OUGH, C.S. Analysis de vinos y mostos. Zaragoza: Editorial Acribia, 1976. 158p.

[2] AUGUSTE, M.H. Application de la chromatographie en phase liquide à haute pression à l'analyse des moûts et des vins. 1979. $135 \mathrm{f}$. Tese (Doutorado em Enologia Ampelográfica) - Université de Bordeaux II, Talence.

[3] BERTRAND, A. Recherches sur l'analyse des vins par chromatographie en phase gazeuse. 1975. $291 \mathrm{f}$. Tese (Doutorado em Enologia) - Université de Bordeaux II, Talence.

[4] BORGOGNO, L.; TARETTO, E.; BOLOGNA, P.; ARNULFO, C.; MORANDO, A. La maturazione dell'uva. Vignevini, Bologna, v.3, n.11, p.59-65, 1984.
[5] CÀSTINO, M. La qualità dell'uva. Vini d'Italia, Brescia, v.34, n.5, p.23-40, 1992.

[6] CHAMPAGNOL, F. Eléments de physiologie de la vigne et de viticulture générale. Montpellier: Imprimerie Déhan, 1984. 351p.

[7] FREGONI, P. Viticoltura di qualità. Lungodige Galtorossa: Informatore Agrário, 1998. 707p.

[8] GALET, P. Précis d'ampélographie pratique. Montpellier: Imprimerie Déhan, 1976. 266p.

[9] HIDALGO, L. Tratado de viticultura general. Madrid: Ediciones Mundi-Prensa, 1993. 983p.

[10] IDE, G.M.; RIZZON, L.A.; DAUDT, C.E. Influência do tempo de maceração do vinho Isabel e Merlot. Boletim da Sociedade Brasileira de Ciência e Tecnologia de Alimentos, Campinas, v.27, n.2, p.88-95, 1993.

[11] MANDELLI, F.; MIELE, A.; RIZZON, L.A.; ZANUZ, M.C. Efeito da poda verde sobre os compostos fenólicos do vinho Merlot. In: Congresso Latino-Americano de Viticultura e Enologia, 6/, Jornadas Vitivinícolas, 5., 1994, Santiago. Anais. Santiago: ASSOCIACIÓN NACIONAL DE INGENIEROS AGRÓNOMOS ENÓLOGOS/ FACULTAD DE AGRONOMIA/UNIVERSIDAD CATÓLICA DE CHILE, 1994. P.444-448.

[12] MINISTĖRE DE L 'AGRICULTURE, DE LA PÊCHE ET DE L'AlimentATION. Catalogue des varietés de clones de vigne cultivés en France. Le Grau du Roi, ENTAV, 1995. 357p.

[13] OFFICE INTERNATIONAL DE LA VIGNE ET DU VIN. Codes des caractères descriptifs des variétes et espèces des Vitis. Paris: Office International de la Vigne et du Vin, 1985. n.p.

[14] PERKIN-ELMER. Analytical methods for atomic absortion spectrophotometry. Norwalk: PerkinElmer, 1976. 432p.

[15] RIBÉREAU-GAYON, P.; STONESTREET, E. Le dosage des anthocyanes dans les vins rouges. Bulletin de la Societé Chimique de France, Paris, v.9, n.419, p.2649-2652, 1965.

[16] RIBÉREAU-GAYON, P.; STONESTREeT, E. Dosage des tanins du vin rouge et détermination de leur structure. Chimie Analytique, Paris, v. 48, n. 4, p. 188-196, 1966.

[17] RIBÉREAU-GAYON, P.; PEYNAUD, E.; RIBÉREAUGAYON, P.; SUDRAUD, P. Sciences et techniques du vin. Paris: Dunod, 1976, v.1, 671p.

[18] RIBÉREAU-GAYON, P.; DUBOURDIEU, D.; DONĖCHE, B.; LONVAUD, A. Traité d'Oenologie. 1.Microbiologie du vin. Vinifications. Dunod: Paris, 1998. 617p.

[19] RIZZON, L.A. Composição química dos vinhos da Microrregião Homogênea Vinicultora de Caxias do Sul (MRH 311) - Compostos voláteis. Bento Gonçalves: EMBRAPA - CNPUV, 1987. 4p. (EMBRAPACNPUV. Comunicado Técnico, 5).

[20] RIZZON, L.A.; MIELE, A.; MENEGUZZO, J.; ZANUZ, M.C. Efeito de três processos de vinificação sobre a composição química do vinho Cabernet Franc. Pesquisa Agropecuária Brasileira, Brasília, v.34, n.7, p.1285-1293, 1999. 